\title{
Satellite Observations of the Seasonal Evolution of Total Precipitable Water Vapour over the Mediterranean Sea
}

\author{
J. L. Palau, ${ }^{1}$ F. Rovira, ${ }^{1}$ and M. J. Sales ${ }^{2}$ \\ ${ }^{1}$ Centro de Estudios Ambientales del Mediterráneo (CEAM), Parc Tecnolòic, C/Charles R. Darwin, No. 14, Paterna, \\ 46980 València, Spain \\ ${ }^{2}$ MODELIZA, Parc Científic de la Universitat de València, C/Catedrático Agustín Escardino, $n^{\circ}$ 9, Paterna, \\ 46980 València, Spain \\ Correspondence should be addressed to J. L. Palau; joseluis@ceam.es
}

Received 30 November 2016; Accepted 2 March 2017; Published 29 March 2017

Academic Editor: Xiaofeng Li

Copyright (c) 2017 J. L. Palau et al. This is an open access article distributed under the Creative Commons Attribution License, which permits unrestricted use, distribution, and reproduction in any medium, provided the original work is properly cited.

\begin{abstract}
This study shows satellite observations and new findings on the time and spatial distribution of the Total Precipitable Water (TPW) column over the Mediterranean Sea throughout the year. Annual evolution and seasonality of the TPW column are shown and compared to the estimated net evaporation over the Mediterranean Sea. Daily spatiotemporal means are in good agreement with previous short-term field campaigns and also corroborate hypothesis and conclusions reached from previous mesoscale modelling studies: (a) from a meteorological point of view, Mediterranean Basin should be considered as two different subbasins (the Western and the Eastern Mediterranean); (b) accumulation processes may affect the radiative balance at regional scale and the summer precipitation regimes. Furthermore, these satellite observations constitute strong empirical evidences that, (a) from late May to early October, contrary to what happens in the Eastern Mediterranean Basin (EMB), there is a net accumulation of TPW on the Western Mediterranean Basin (WMB) that favours the instability of the atmosphere, (b) there is a seasonal anticorrelation between the seasonal variability of the TPW column over the two Mediterranean subbasins, (c) solar radiation can not be the only driver for the annual variability of the TPW column over the Mediterranean Sea, and (d) both previous features are seasonally dependent and, therefore, their effects on the TPW column are attenuated by annual variability.
\end{abstract}

\section{Introduction}

The Mediterranean Basin presents certain orographic and biogeographic peculiarities that reinforce the importance of atmospheric mesoscale processes in its climate. It also has a long history of environmental changes as well as a presentday strong anthropogenic pressure but, in spite of that, it is one of the most important biodiversity hotspots in the world [1]. Therefore the study of the availability of the Total Precipitable Water (TPW) over the Mediterranean Basin, the main sources and atmospheric pathways for water vapour imports (and exports) into (and from) the Mediterranean troposphere, and their seasonal variability in the Mediterranean Basin are relevant issues, among others, to integrate feedback driving climate change in terms of precipitation regimes, radiative balance, secondary pollutants production, ventilation conditions, and so forth $[2,3]$.
This study is based on direct systematic measurements of the TPW column and the monthly mean net evaporation over the Mediterranean Sea obtained from the Climate Forecast System Reanalysis (CFSR, NCEP, National Centre for Environmental Prediction)

\section{Background}

The origin and motivation of this seasonal characterisation lie in different empirical (field campaigns and atmospheric measurements) and numerical experiments during, at least, the last twenty-five years.

Since the early 90 s, satellite data yield vertically integrated tropospheric ozone values over the Western Mediterranean of the order of 50 to 55 Dobson units during June-August (average of $125-150 \mu \mathrm{g} / \mathrm{m}^{3}$ within an $8 \mathrm{~km}$ column) which corresponded to a difference of 10 Dobson units when 
comparing with the mean values measured simultaneously over the Eastern Mediterranean [4].

On those days, different international field campaigns (Table 1) in the Western Mediterranean evidenced the prevalence of mesoscale circulations, with marked diurnal cycles and large spatial dimensions, under summer conditions.

Different EU-funded projects (Table 1) put in evidence that not only were these diurnal cycles of mesoscale circulations strongly linked to air pollution but they were the main drivers of the vertical recirculation of atmospheric pollutants along and over the Western Mediterranean coasts [5-8]. As a result, further evidences on high regional background tropospheric ozone were recorded from different groundbased and airborne measurements during large field campaigns which took place in Western, Central, and Eastern Mediterranean areas [6].

Later on, with the development of the high-performance computing devices and of the numerical modelling codes at the mesoscale, different numeric and computer exercises corroborated the feasibility of this vertical recirculation [912].

With the pass of the years and with longer time-series of (measured) near-surface pollutants, it was possible to identify, define, and quantify the, so-called, accumulation cycles which could explained the ozone anomaly previously published by Fishman in 1990 [13, 14].

Moreover, since the early nineties, with the availability of the Water Vapour channel on board of different geostationary satellites, some authors, like Holmlund [15, 16], Laurent [17], Le Marshall et al. [18], Merrill [19], Tokuno [20], Velden et al. [21], and Rattenborg [22], have shown that wind information can be derived from geostationary satellite water vapour images using the movement of cloud and water vapour as tracers of opportunity. This information is useful to determine both upper-level moisture content and the wind fields that correspond to the water vapour layers [23].

Since the early 2000s, a new generation of high-resolution instruments aboard on new meteorological satellites enabled the possibility of studying a large amount of different chemical species and meteorological magnitudes from above. Soon, the first spatial patterns of some trace gases, like the water vapour, also show both the daily oscillation of air masses all over the Western Mediterranean Sea and its seasonality [3].

The observed daily pattern consisted of maximum values of the TPW along the inland coastal mountain ranges all around the Western Mediterranean Basin and, driven by nocturnal katabatic flows from the coastal mountains towards the sea, maximum values of the TPW were allocated over the sea. The same data showed the seasonality of this pattern reinforcing the suspicion that this was further evidence of the vertical recirculation and, therefore, the lack of net ventilation in the lower troposphere over this Western side of the Mediterranean [3].

Further on, more recent studies have also evidenced, for example, using reanalysis data, the spatial extent and strength of the (vertical and horizontal) mesoscale circulations in this region of the Mediterranean Sea and also the daily pulsation and seasonal variation of the surface divergence field over the Western Mediterranean Sea [24]. In this subbasin (Figure 1), during the night drainage winds flow from the coasts towards the sea, generating a net convergence and weak upwelling motions and, during the daytime, the activation of sea breezes (advection of air masses over the sea towards inland) causes a net divergence of the horizontal wind field and a generalised subsidence of the air masses aloft driving, during the afternoon, a quasi-synchronized clockwise rotation of the wind direction of sea breezes all around the Western Mediterranean coasts [24].

Thanks to the availability of longer time-series obtained from satellite observations, now the analysis and characterisation of the accumulation (recharge), ventilation (advection), and discharge (rain) of the TPW and, as one of the direct consequences, its variability along the years and its implication on the hydrological cycles within the Western and Eastern Mediterranean begin to be possible.

This manuscript aims to show some of the preliminary steps followed towards a seasonal characterisation of the TPW over the Mediterranean. In the near future, authors hope to be able to finish the complete study on this regard identifying and quantifying key-parameters explaining the behaviour described in this advance of our findings.

\section{Data Bases}

The TPW column dataset (MOD05_L2) is provided by the MODIS instrument (MODerate Resolution Imaging Spectroradiometer) on board the TERRA Sun-synchronous satellite (formally known as EOS AM-1). TERRA circles Earth in a polar orbit, perpendicular to the direction of Earth's spin, at $705 \mathrm{~km}$ altitude crossing the equator southward (descending) at 10:30 Local Time (LT) and again northward (ascending) at 22:30 LT. During the daytime, a near-infrared algorithm is applied over clear land areas of the globe and above clouds over both land and ocean. Over clear ocean areas, water vapour estimates are provided over the extended glint area. An infrared algorithm for deriving atmospheric profiles is also applied both day and night. Level 2 data are generated at the $1 \mathrm{~km}$ spatial resolution of the MODIS instrument using the near-infrared algorithm during the day and at $5 \times 5$ onekilometer resolution both day and night using the infrared algorithm when at least nine Fields Of View (FOVs) are cloud-free.

The dataset used in this study consist of the diurnal time pass of TERRA over the Mediterranean Sea (i.e., around 11:00 LT) and, thus, this study is based on one measured data item by day covering an eleven-year period (2000-2010).

The estimated net evaporation over the Mediterranean Sea (defined as evaporation minus precipitation) has been calculated as monthly mean from the NCEP (National Centre for Environmental Prediction) Climate Forecast System Reanalysis (CFSR) dataset, with a resolution of $0.5^{\circ} \times 0.5^{\circ}$ [25].

\section{Results and Discussion}

At first, the visual inspection of the persistence of a clear TPW spatial heterogeneity over the whole Mediterranean Sea suggested the idea of choosing two equal areas centred on each part of the dipole formed by the maximum and minimum 


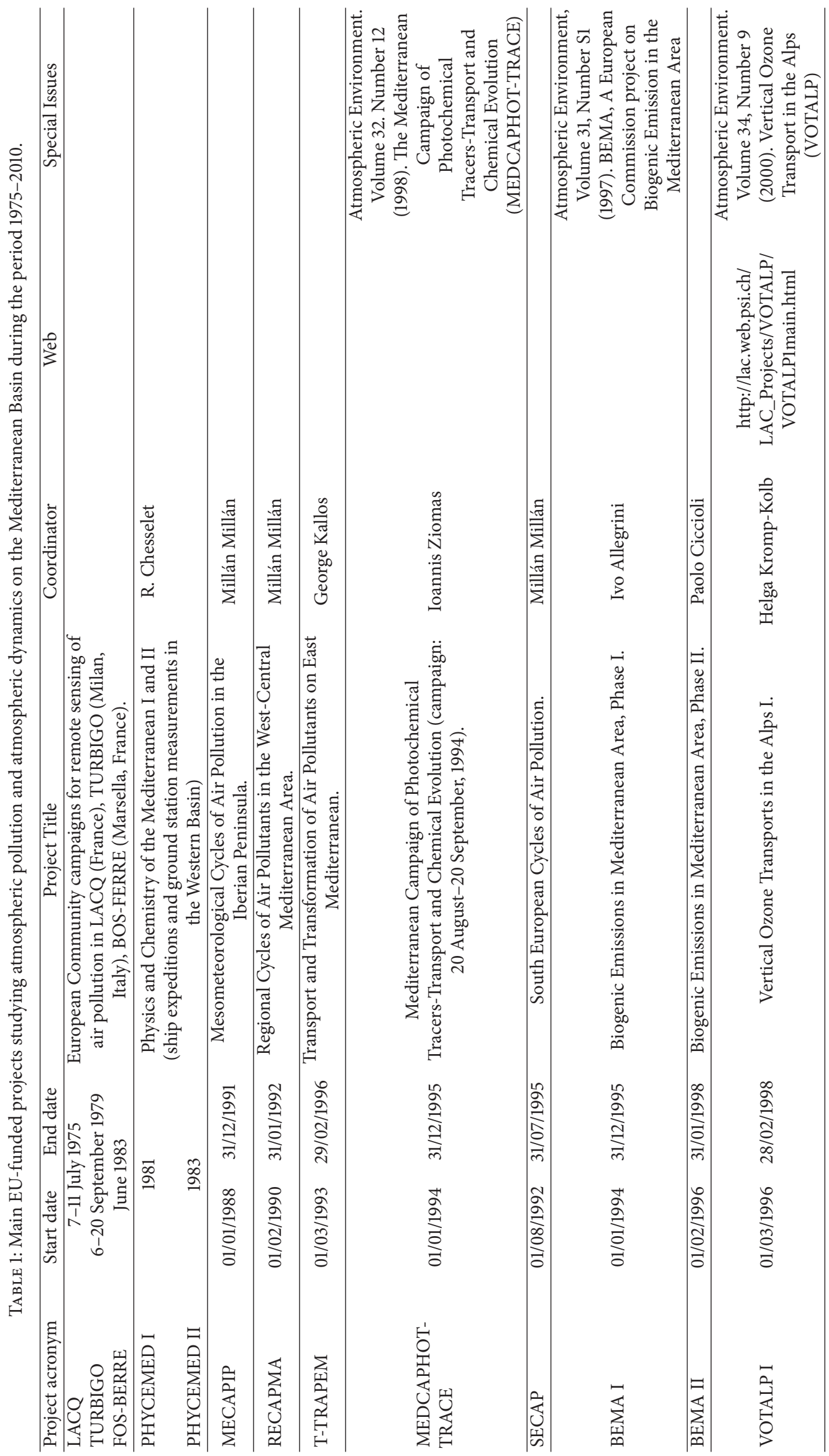




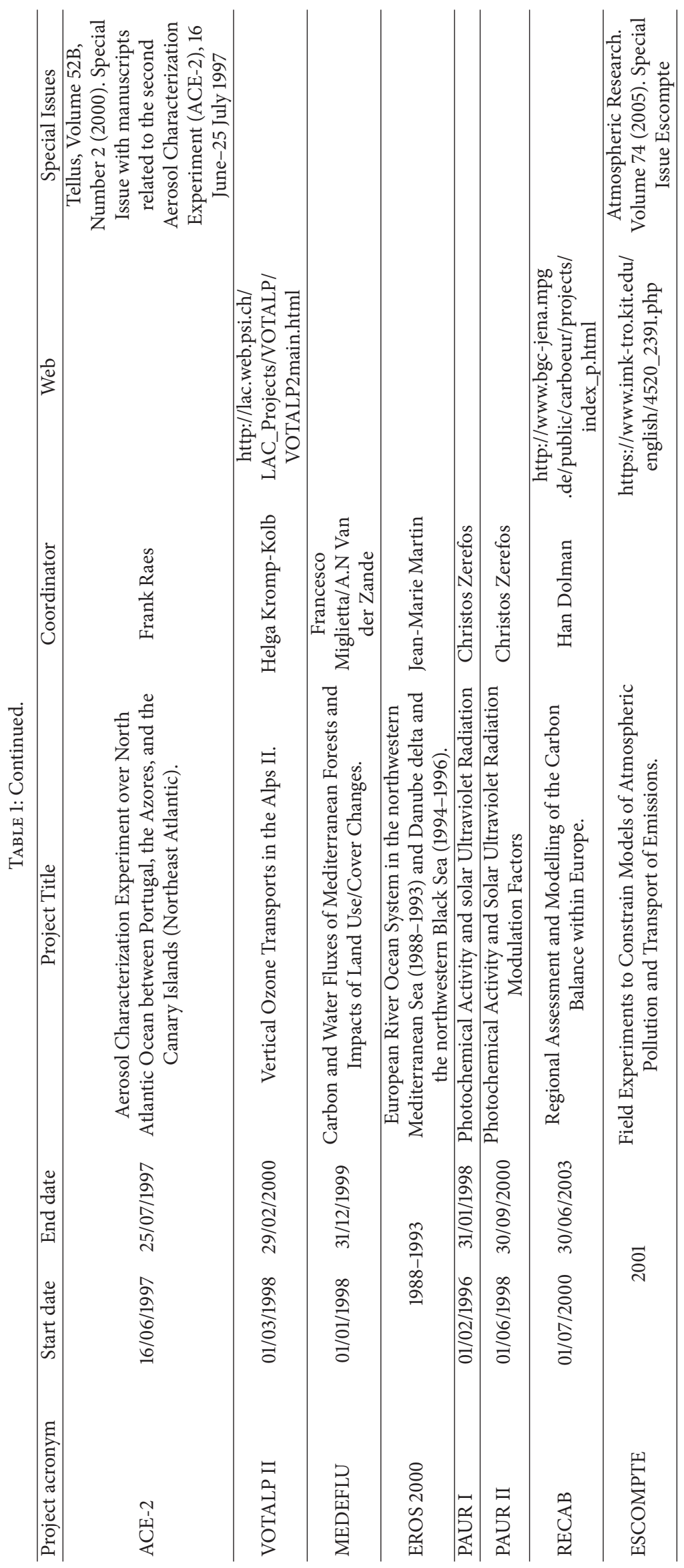




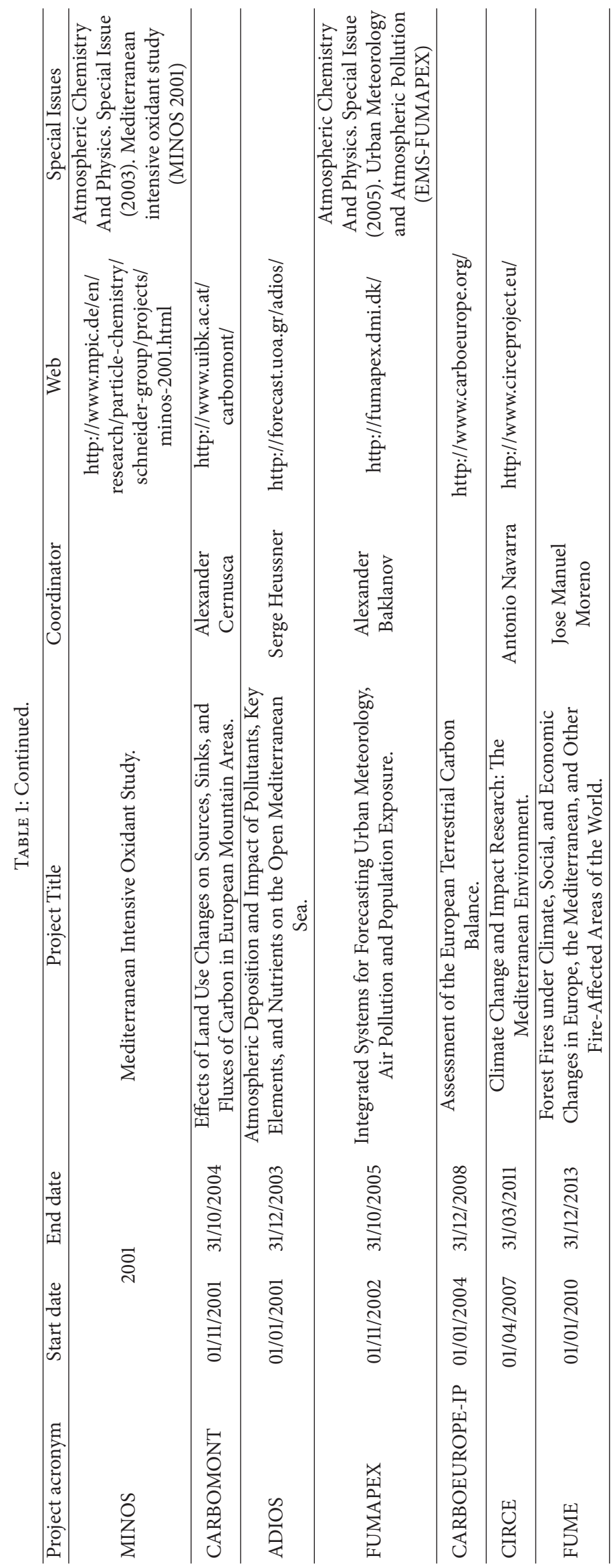




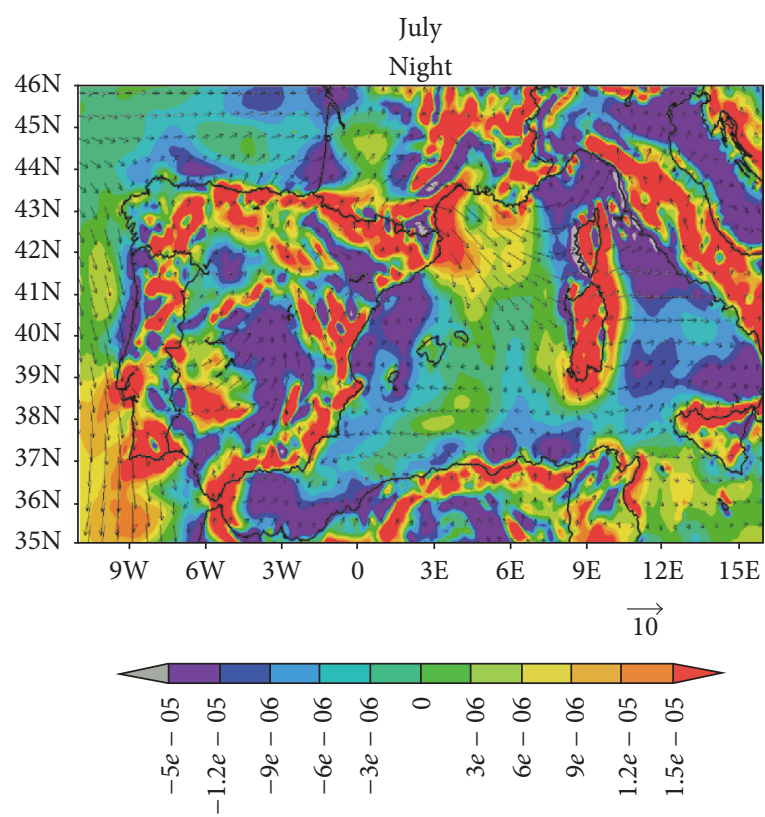

(a)

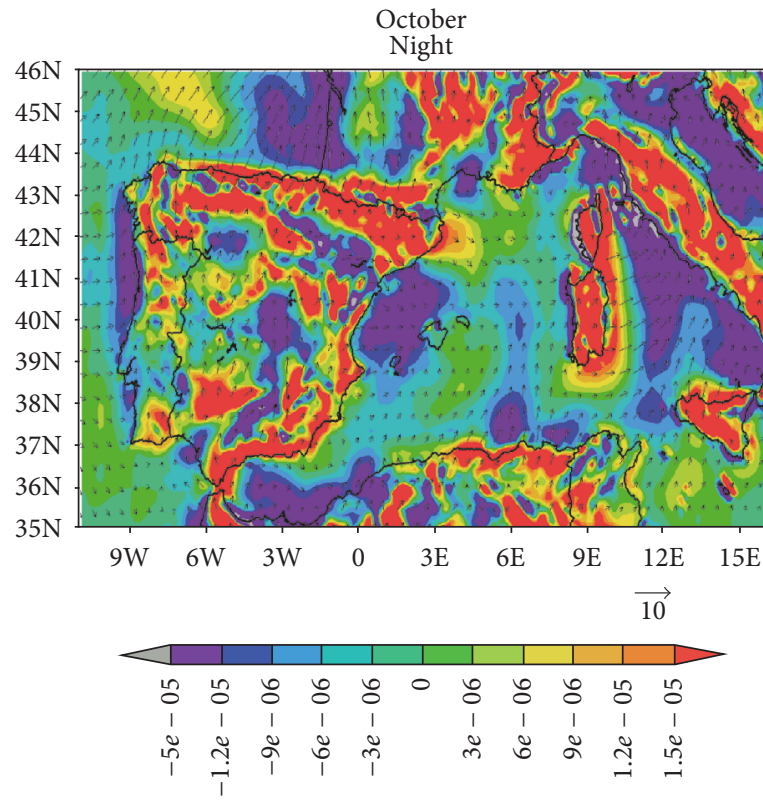

(c)

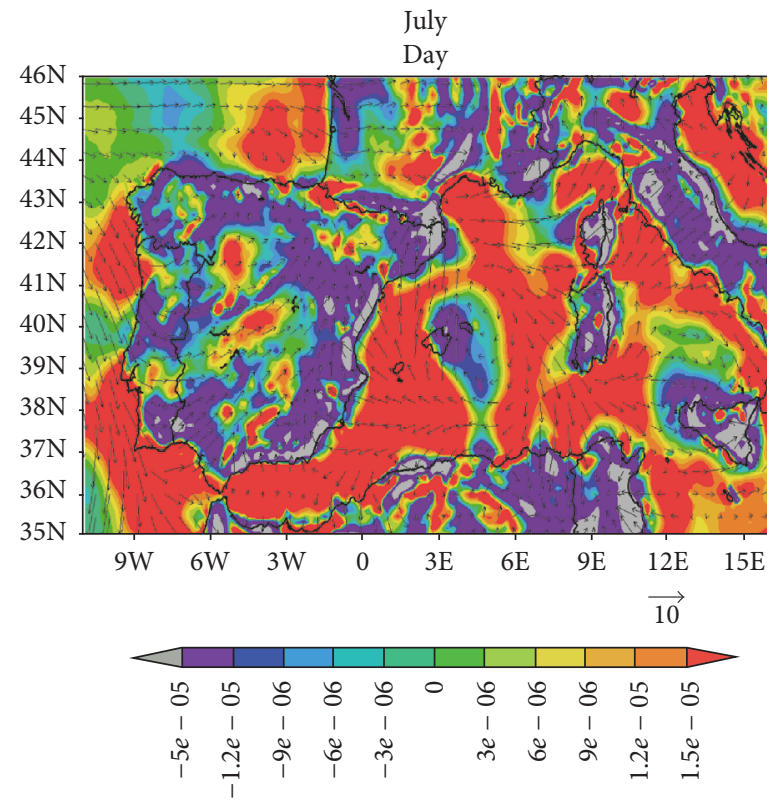

(b)

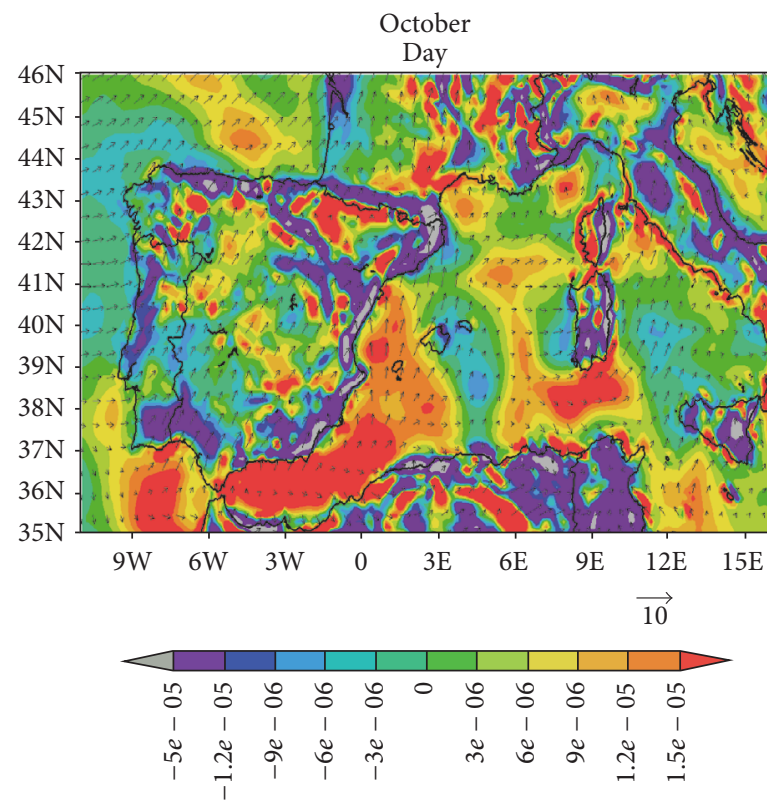

(d)

FIGURE 1: Mean divergence/convergence (red/blue colors) and horizontal wind field (vectors) for the 10-year period 1998-2007. Daily pulsation between night and day $((\mathrm{a}, \mathrm{c})$ and $(\mathrm{b}, \mathrm{d}))$ is more evident during summertime than during autumn/winter time $((\mathrm{a}, \mathrm{b})$ and $(\mathrm{c}, \mathrm{d}))$. Scale colors of the divergences are represented $(1 / \mathrm{s})$. The scale for the vector wind field is $10 \mathrm{~m} / \mathrm{s}$.

TPW monthly mean values, calculated simultaneously on the western and eastern sides, respectively (Figure 2).

The rectangle over the Western Mediterranean Basin (WMB) was defined within $0.2^{\circ} \mathrm{E}$ to $8.2^{\circ} \mathrm{E}$ and $37.1^{\circ} \mathrm{N}$ to $41.1^{\circ} \mathrm{N}$. In the same way, on the Eastern Mediterranean Basin (EMB), the rectangle extends from $26.6^{\circ} \mathrm{E}$ to $34.6^{\circ} \mathrm{E}$ and $31.9^{\circ} \mathrm{N}$ to $35.9^{\circ} \mathrm{N}$ (Figure 3). Both rectangles cover similar areas to assure enough data for averaging and the intercomparison between them.
To obtain the daily means (one value per day), we calculated the daily spatial mean of the TPW column and net evaporation in the two selected rectangles at the two sides of the Mediterranean Sea (boxes at Figure 2). The spatial average of the diurnal (around 11:00 LT) daily data provides the 11-year time-series of daily mean values of TPW column on each side of the Mediterranean (not shown). To avoid the noisy annual evolution obtained and to identify more clearly the seasonal variation of the 11-year period (2000-2010), we calculated the 


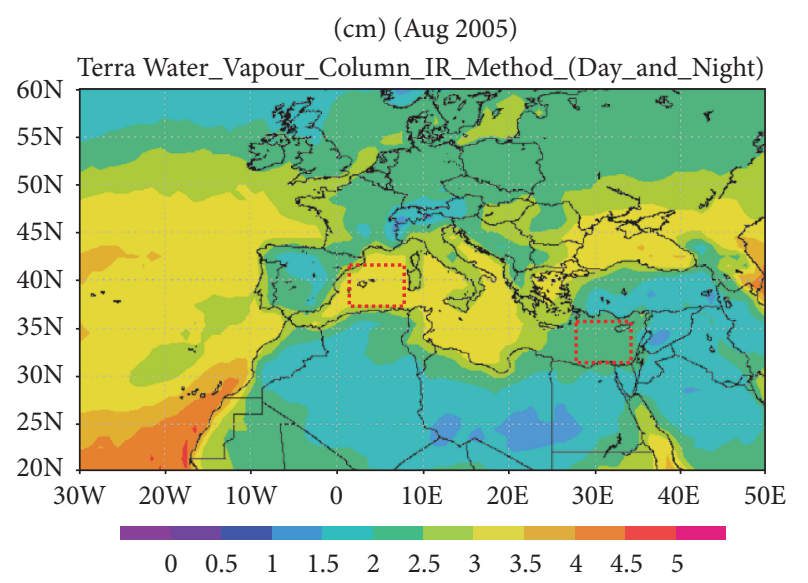

GrADS: COLA/IGES

2008-05-10-06:14

FIgURE 2: Mean values of the TPW column measured by TERRA during August 2005. Red squares indicate the two areas of study (where mean time-series of TPW values were calculated). Scale units are $\mathrm{cm}$.

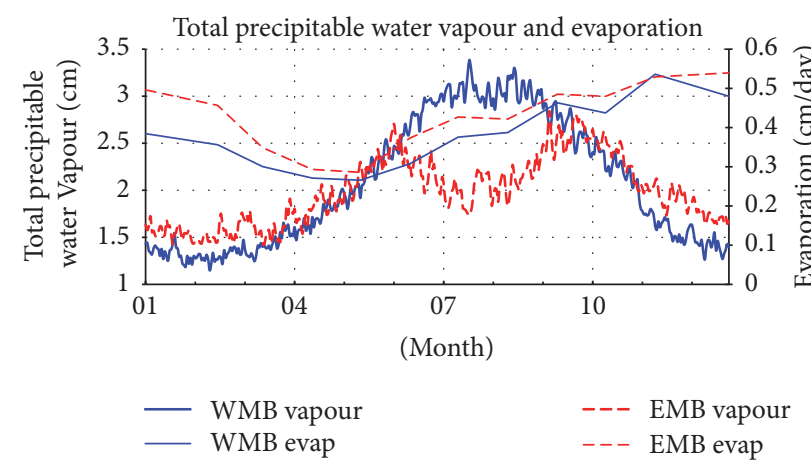

FIGURE 3: Daily spatiotemporal mean within the two selected boxes and over eleven years (2000-2010) of net evaporation (thin and thindashed lines) and column of TPW column (bold and dotted-bold bell-shaped lines).

mean year by averaging the daily values of the TPW column observed from MODIS and the net evaporation estimated using the CFSR dataset (Figure 3).

While over the WMB the mean TPW column has one maximum centred on the summer season (July-August), over the EMB there are two maxima at the end of spring season (May-June) and at the beginning of autumn (SeptemberOctober) season (bold and dotted-bold bell-shaped red lines in Figure 3). Thus, annual oscillation of the TPW column at the EMB does not follow the annual variation of solar irradiation (with a maximum at summer and a minimum during winter season).

Regarding the spatial mean of net evaporation averaged over the same eleven-year period over both sides of the Mediterranean, we obtained minimum values in April, May, and June and maximum values reaching on NovemberDecember.

According to the fact that climatologic SST reach higher values on the EMB than on WMB [26], mean net evaporation on the eastern side of the Mediterranean Sea remains higher than on the Western side throughout the year. However, net evaporation from the sea and the TPW column over the same regions are, in general terms, uncorrelated and even anticorrelated during some months of the year.

The TPW column reaches higher values in the EMB than in the WMB for most of the year except during summer season. During summer season, evaporation on both sides of the Mediterranean Sea increases while the TPW column over the EMB decreases. Moreover, mean time-series clearly show the seasonal anticorrelation between the TPW column at the $\mathrm{EMB}$ and the WMB.

These features can not be attributed only to a higher evaporation rates from the sea surface since climatic values of SST in the EMB is about three degrees higher than in the $\mathrm{WMB}$ and, furthermore, near-surface wind speeds are not so different on both sides of the Mediterranean. Rather it might be because, during the summer months, while in the Western Basin (under the influence of the Azores anticyclone) mesoscale vertical recirculation (low net ventilation conditions) is the most recurrent meteorological characteristic, and in the EMB advective conditions prevail in the midupper troposphere due to the Asian Monsoon system, that is, higher ventilation conditions with high rates of renewal of air masses aloft [2, 27-29].

On the contrary, during wintertime troposphere in the Western Basin is much more ventilated than in summer whereas in the eastern side the extension of the Siberian Anticyclone system favours stagnation conditions in the troposphere [27-29]. This might be why, at this time of the year, the values of TPW column in the Eastern Basin are higher than in the Western Basin.

That said it is remarkable that net evaporation and TPW column are not unequivocally related over the Mediterranean Sea and that, additional to the solar irradiation and the net evaporation, other seasonally dependent meteorological factors must exist governing both annual evolutions of the TPW columns.

Furthermore, if all the abovementioned patterns of the TPW columns over the two Mediterranean subbasins are more strongly driven by the prevailing mesometeorology rather than by local processes (e.g., the net evaporation), then their spatiotemporal variability must be in good concordance with previous measurements and modelling experiments on both sides of the Mediterranean Sea.

Using these observations, further detailed and quantitative analysis will be done using different statistical techniques. Authors plan to continue this study to characterise the spatial and seasonal differences of TPW column in both Mediterranean basins and the possible correlation between this type of instability of the atmosphere (due to TPW accumulation processes) and the occurrence of some weather extremes and air quality episodes, in the Mediterranean Basin.

\section{Conclusions}

The annual evolution and spatial distribution of the Total Precipitable Water (TPW) vapour column over the Mediterranean Sea is seasonally dependent and different on both 
sides (western and eastern) of the basin, coherently with different previous studies performed in the Mediterranean Basin since the nineties. Moreover, the 11-year averaged values show a seasonal anticorrelation between the variability of the TPW column over the two Mediterranean subbasins.

Solar radiation can not be the only driver for the annual variability and the spatial heterogeneities of the observed TPW column over the Mediterranean Sea since there is no correlation neither with the evaporation from the sea surface nor with the sea surface temperature.

Considering the previous studies performed in the Mediterranean Basin, it seems reasonable to propose as possible drivers the (seasonally dependent) mesoscale processes that prevail in the region, for example, the daily cycles of air masses and the poor ventilation conditions that lead accumulation processes of air masses over the Mediterranean Sea and coastal areas (i.e., accumulation of evaporated water vapour and emitted pollutants).

More and more detailed studies are necessary to deepen the direct and indirect consequences of the observed seasonal variations and spatial heterogeneities of TPW values over the Mediterranean Sea. Some different social challenges, for example, floods, draughts, and air quality episodes of secondary pollutants (aerosols, ozone, etc.). might be related, directly or indirectly, to values of TPW column. It is reasonable to hypothesize that the time evolution and spatial distribution of TPW values in the troposphere may be one of the key trigger mechanisms (a) for the sudden heterogeneous and anisotropic instability of the troposphere at the mesoscale under synoptic high pressure conditions, (b) for the development of unpredicted air quality (coastal) episodes, (c) for the variations and heterogeneities of the radiative balance in the basin (since water vapour is a greenhouse gas), and (d) for the spatial heterogeneities and changes in the main chemical mechanisms of formation/degradation of secondary pollutants (since changes in the atmospheric water vapour content drive changes in the concentration values of, among other chemical elements [30], the hydroxyl $\left(\mathrm{OH}^{-}\right)$ and hydroperoxyl $\left(\mathrm{HO}_{2}{ }^{-}\right)$radicals, which are very important elements in the chemistry of tropospheric ozone). On this last aspect, it is worth adding how previous studies on the Aegean Sea (Eastern Mediterranean) have demonstrated the great abundance of hydroxyl radicals in this area and their great importance for the concentrations of tropospheric ozone and methane in the region.

\section{Conflicts of Interest}

The authors declare that they have no conflicts of interest.

\section{Acknowledgments}

The authors would like to thank Dr. Millán Millán, retired senior scientist and executive director of the CEAM Foundation, for his mentoring and his valuable comments and suggestions during the last fifteen years. The CEAM Foundation is supported by the Generalitat Valenciana (Spain). This study has been partially funded by the Spanish Ministry of Science and Technology, through the research projects "MODELISMOS," CGL2010-17623, and "VERSUS," CGL2015-67466$\mathrm{R}$, and the Spanish Excellent Network "GRACCIE-NET" CTM2014-59111-REDC and by the Conselleria de Cultura (Generalitat Valenciana, SPAIN) research project "DESESTRES," PROMETEOII/2014/038.

\section{References}

[1] N. Myers, R. A. Mittermeler, C. G. Mittermeler, G. A. B. da Fonseca, and J. Kent, "Biodiversity hotspots for conservation priorities," Nature, vol. 403, no. 6772, pp. 853-858, 2000.

[2] G. Kallos, C. Mitsakou, A. Alastuey et al., "Mechanisms of climate variability, air quality and impacts of atmospheric constituents in the Mediterranean Region," in Regional Assessment Climate Change in the Mediterranean, A. Navarra and L. Tubiana, Eds., chapter 3, pp. 119-156, Springer, Berlin, Germany, 2013.

[3] M. M. Millán, "Extreme hydrometeorological events and climate change predictions in Europe," Journal of Hydrology, vol. 518, pp. 206-224, 2014.

[4] J. Fishman, C. E. Watson, J. C. Larsen, and J. A. Logan, "Distribution of tropospheric ozone determined from satellite data," Journal of Geophysical Research, vol. 95, no. 4, pp. 35993617, 1990.

[5] M. M. Millán, B. Artíñano, L. Alonso, M. Navazo, and M. Castro, "The effect of meso-scale flows on regional and longrange atmospheric transport in the western Mediterranean area," Atmospheric Environment Part A, General Topics, vol. 25, no. 5-6, pp. 949-963, 1991.

[6] M. Millán, B. Artiñano, L. Alonso, M. Castro, R. FernandezPatier, and J. Goberna, "Meso-Meteorological Cycles of Air Pollution in the Iberian Penisula, (MECAPIP)," Air Pollution Research Report 44, EUR No. 14834, European Commision DG XII/E-1, Brussels, Belgium, 1992.

[7] M. Millán, R. Salvador, E. Mantilla, and B. Artíñano, "Meteorology and photochemical air pollution in Southern Europe: experimental results from EC research projects," Atmospheric Environment, vol. 30, no. 12, pp. 1909-1924, 1996.

[8] J. Cuxart, J. Cunillera, M. A. Jiménez, D. Martínez, F. Molinos, and J. L. Palau, "Study of mesobeta basin flows by remote sensing," Boundary-Layer Meteorology, vol. 143, no. 1, pp. 143$158,2012$.

[9] R. Salvador, M. Millán, E. Mantilla, and J. M. Baldasano, "Mesoscale modelling of atmospheric processes over the western Mediterranean area during summer," International Journal of Environment and Pollution, vol. 8, no. 3-6, pp. 513-529, 1997.

[10] G. Gangoiti, M. M. Millán, R. Salvador, and E. Mantilla, "Longrange transport and re-circulation of pollutants in the western Mediterranean during the project Regional Cycles of Air Pollution in the West-Central Mediterranean Area," Atmospheric Environment, vol. 35, no. 36, pp. 6267-6276, 2001.

[11] G. Pérez-Landa, P. Ciais, M. J. Sanz et al., "Mesoscale circulations over complex terrain in the Valencia coastal region, Spain - part 1: simulation of diurnal circulation regimes," Atmospheric Chemistry and Physics, vol. 7, no. 7, pp. 1835-1849, 2007.

[12] J. L. Palau, G. Pérez-Landa, and M. M. Millán, “Transitional dispersive scenarios driven by mesoscale flows on complex terrain under strong dry convective conditions," Atmospheric Chemistry and Physics, vol. 9, no. 1, pp. 119-131, 2009. 
[13] M. M. Millán, E. Mantilla, R. Salvador et al., "Ozone cycles in the western Mediterranean basin: interpretation of monitoring data in complex coastal terrain," Journal of Applied Meteorology, vol. 39, no. 4, pp. 487-508, 2000.

[14] J. L. Palau and F. Rovira, "A methodology for the characterization of periodicities in nonsteady time series: application to tropospheric ozone recharging cycles in the western Mediterranean basin," Journal of Atmospheric and Oceanic Technology, vol. 29, no. 11, pp. 1644-1656, 2012.

[15] K. Holmlund, "Operational water vapor wind vectors from Meteosat imagery," in Proceedings of the 2nd Workshop on Wind Extraction from Operational Satellite Data, pp. 77-84, EUMETSAT, Tokyo, Japan, 1993.

[16] K. Holmlund, "Half hourly wind data from satellite derived water vapour measurements," Advances in Space Research, vol. 16, no. 10, pp. 59-68, 1995.

[17] H. Laurent, "Wind extraction from Meteosat water vapor channel image data," Journal of Applied Meteorology, vol. 32, no. 6, pp. 1124-1133, 1993.

[18] J. Le Marshall, N. Pescod, R. Seecamp, K. Puri, C. Spinoso, and R. Bowen, "Local estimation of GMS-5 water vapor motion vectors and their application to australian region numerical weather prediction," Australian Meteorological Magazine, vol. 48, no. 1, pp. 73-77, 1999.

[19] R. Merrill, "Advances in automated production of wind estimates from Geostationary satellite imagery," in Proceedings of the 4th Conference on Satellite Meteorology, pp. 246-249, San Diego, Calif, USA, 1989.

[20] M. Tokuno, "Operational system for extracting cloud motion and water vapor motion winds from GMS5 image data," in Proceedings of the 3rd IWW, pp. 21-30, 1996.

[21] C. S. Velden, C. M. Hayden, S. J. Nieman, W. P. Menzel, S. Wanzong, and J. S. Goerss, "Upper-tropospheric winds derived from geostationary satellite water vapor observations," Bulletin of the American Meteorological Society, vol. 78, no. 2, pp. 173195, 1997.

[22] M. Rattenborg, "Operational Meteosat wind products towards MSG," in Proceedings of the 5th International Winds Workshop, EUMETSAT, Lorne, Australia, 2000.

[23] S. K. Deb, C. M. Kishtawal, P. K. Pal, and P. C. Joshi, "Water vapor winds from Kalpana VHRR: a new approach," in Proceedings of the 9th International Winds Workshop, Annapolis, Md, USA, April 2008.

[24] J. L. Palau and F. Rovira, "Meso-alpha scale tropospheric interactions within the western mediterranean basin: statistical results using 15-year NCEP/NCAR reanalysis dataset," Advances in Meteorology, vol. 2015, Article ID 302746, 11 pages, 2015.

[25] S. Saha, S. Moorthi, X. Wu et al., NCEP Climate Forecast System Version 2 (CFSv2) 6-Hourly Products, Research Data Archive at the National Center for Atmospheric Research, Computational and Information Systems Laboratory, 2011.

[26] H. Bolle, Ed., Mediterranean Climate: Variability and Trends, Springer, Berlin, Germany, 2003.

[27] Meteorological Office, Weather in the Mediterranean, vol. 1, General Meteorology, Code no. 40-142-1-62, Air Ministry, Meteorological Office, Her Majesty's Stationery Office, London, UK, 1962.

[28] M. M. Millán, R. Salvador, E. Mantilla, and G. Kallos, "Photooxidant dynamics in the Mediterranean basin in summer: results from European research projects," Journal of Geophysical Research Atmospheres, vol. 102, no. 7, pp. 8811-8823, 1997.
[29] I. Levy, U. Dayan, and Y. Mahrer, "A five-year study of coastal recirculation and its effect on air pollutants over the East Mediterranean region," Journal of Geophysical Research: Atmospheres, vol. 113, no. 16, Article ID D16121, 2008.

[30] B. J. Finlayson-Pitts and J. N. Pitts Jr., Chemistry of the Upper and Lower Atmosphere, Academic Press, Cambridge, Mass, USA, 2000. 

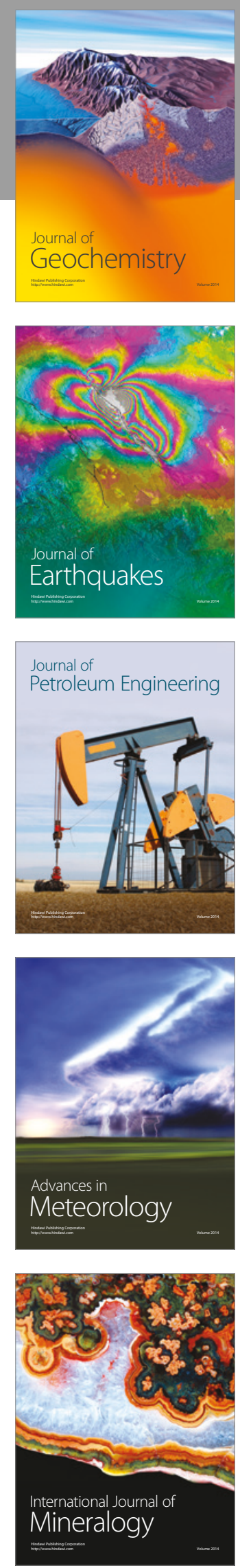
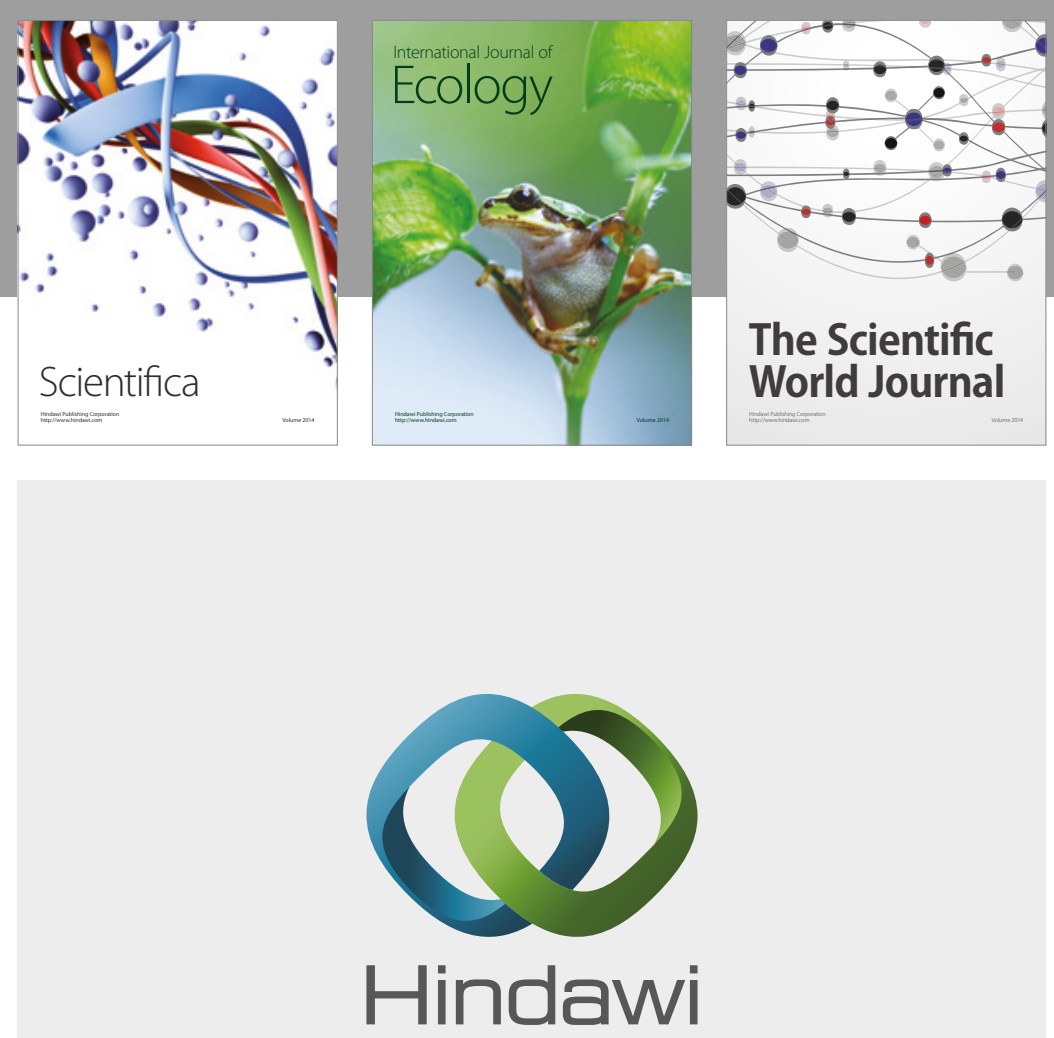

Submit your manuscripts at

https://www.hindawi.com
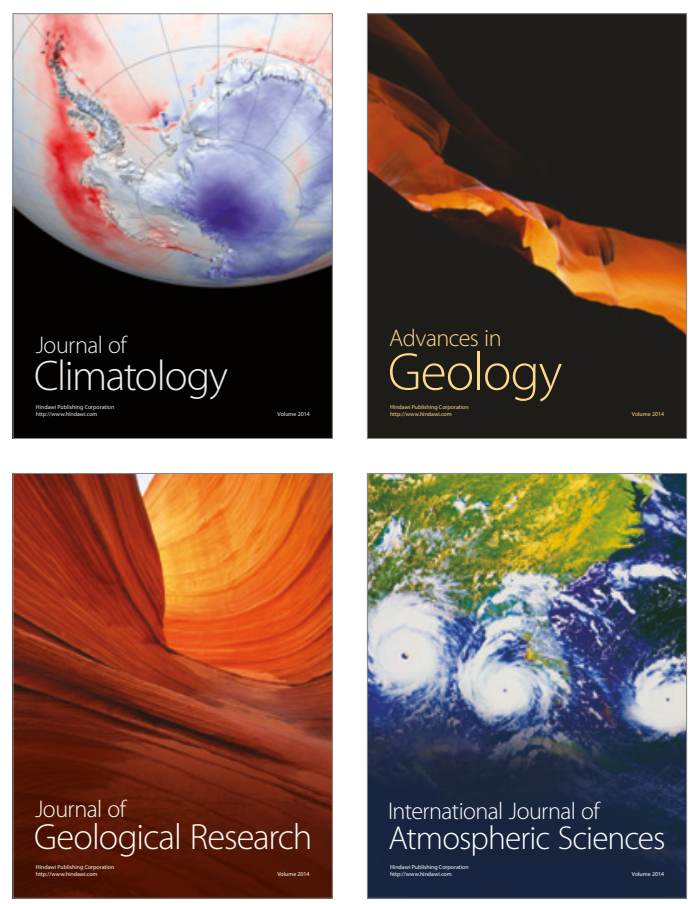

The Scientific

World Journal
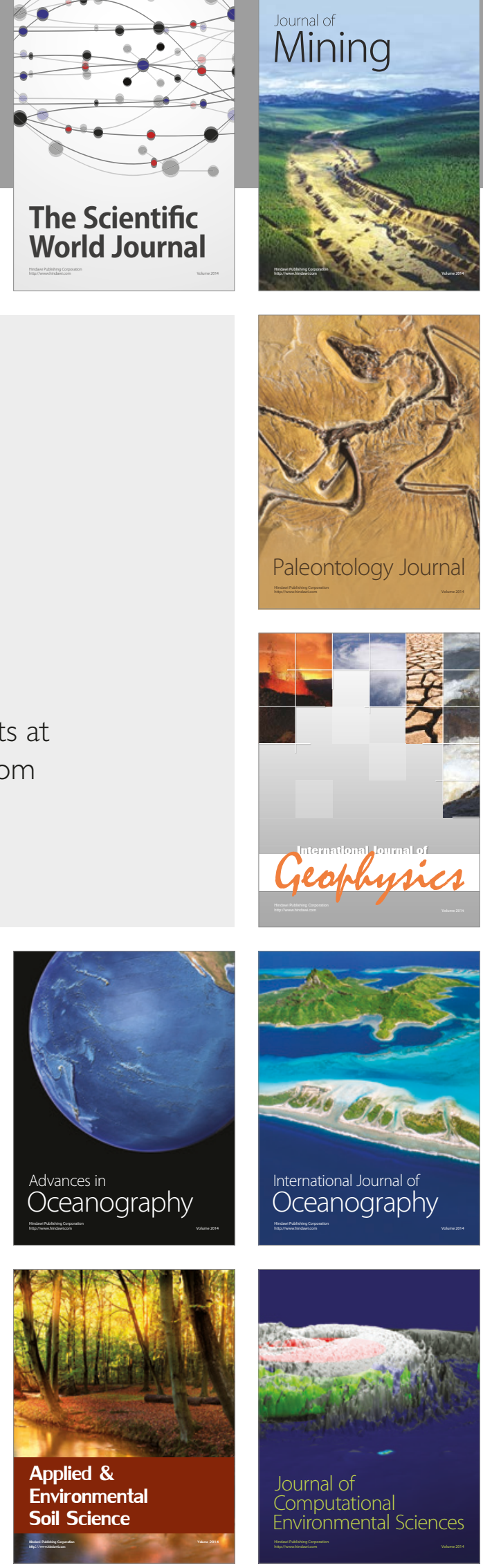